Pilot Study

\title{
Response to Pulsed and Continuous Radiofrequency Lesioning of the Dorsal Root Ganglion and Segmental Nerves in Patients with Chronic Lumbar Radicular Pain
}

Thomas T. Simopoulos, MD, Jan Kraemer, MD, Jyotsna V. Nagda, MD, Musa Aner, MD, and Zahid H. Bajwa, MD

From: Beth Israel Deaconess Medical Center, Harvard Medical School, Boston, MA

Dr. Simopoulos is an Instructor and Physician, Department of Anesthesia, Critical Care, and Pain Medicine, Beth Israel Deaconess Medical Center, Harvard Medical School, Boston, MA.

Dr. Kraemer is with the Department of Anesthesia, Critical Care, and Pain Medicine, Beth Israel Deaconess Medical Center, Harvard Medical School, Boston, MA. Dr. Nagda is an Instructor, Department of Anesthesia, Critical Care, and Pain Medicine, Beth Israel Deaconess Medical Center, Harvard Medical School, Boston, MA. Dr. Aner is a Pain Management Physician, Department of Anesthesiology and Critical Care, Beth Israel Deaconess Medical Center, Harvard Medical School, Boston, MA. Dr. Bajwa is an Assistant Professor and Staff Physician, Department of Anesthesiology and Critical Care, Beth Israel Deaconess Medical Center, Harvard Medical School, Boston, MA.

Address correspondence: Thomas T. Simopoulos, MD Beth Israel Deaconess Medical Center 330 Brookline Ave. Boston, MA 02215

E-mail: tsimopou@bidmc.harvard.edu

Disclaimer: There was no external funding in the preparation of this manuscript.

Conflict of interest: None.

Manuscript received: $11 / 20 / 2007$

Revisions received: 01/10/2008 Accepted for publication: 01/28/2008

Free full manuscript: www.painphysicianjournal.com
Objectives: We aimed to prospectively evaluate the response and safety of pulsed and continuous radiofrequecy lesioning of the dorsal root ganglion/segmental nerves in patients with chronic lumbosacral radicular pain.

Methods: Seventy-six patients with chronic lumbosacral radicular pain refractory to conventional therapy met the inclusion criteria and were randomly assigned to one of 2 types of treatment, pulsed radiofrequency lesioning of the dorsal root ganglion/segmental nerve or pulsed radiofrequency followed immediately by continuous radiofrequency. Patients were carefully evaluated for neurologic deficits and side effects. The response was evaluated at 2 months and was then tracked monthly. A Kaplan-Meier analysis was used to illustrate the probability of success over time and a Box-Whisker analysis was applied to determine the mean duration of a successful analgesic effect.

Results: Two months after undergoing radiofrequency treatment, $70 \%$ of the patients treated with pulsed radiofrequency and $82 \%$ treated with pulsed and continuous radiofrequency had a successful reduction in pain intensity. The average duration of successful analgesic response was 3.18 months $( \pm 2.81)$ in the group treated with pulsed radiofrequency and 4.39 months $( \pm 3.50)$ in those patients treated with pulsed and continuous radiofrequency lesioning. A Kaplan-Meier analysis illustrated that in both treatment groups the chance of success approached $50 \%$ in each group at 3 months. The vast majority of patients had lost any beneficial effects by 8 months. There was no statistical difference between the 2 treatment groups. No side effects or neurological deficits were found in either group.

Conclusion: Pulsed mode radiofrequency of the dorsal root ganglion of segmental nerves appears to be a safe treatment for chronic lumbosacral radicular pain. A significant number of patients can derive at least a short-term benefit. The addition of heat via continuous radiofrequency does not offer a significant advantage. A randomized controlled trial is now required to determine the effectiveness of pulsed radiofrequency.

Key words: Pulsed radiofrequency lesioning, dorsal root ganglion, segmental nerve, continuous radiofrequency lesioning, chronic lumbosacral radicular pain

Pain Physician 2008; 11:137-144 


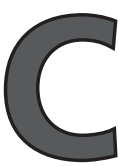
hronic lumbosacral radicular pain is a common and challenging clinical entity problem in pain management centers. If this condition does not respond to conservative measures such as physiotherapy, transcutaneous electrical nerve stimulation, medication treatment, or epidural steroid injections, more invasive approaches such as percutaneous or open corrective spine surgery or spinal cord stimulation are frequently employed. Not uncommonly, an appreciable number of patients either do not obtain satisfactory relief or are not candidates for any of these therapeutic options. Many receive palliation of their symptoms from periodic depo-corticosteroid nerve root blocks with only very short-lived relief.

Continuous radiofrequency lesioning (CRFL) of the dorsal root ganglion (DRG) has been suggested as a potential therapeutic option for chronic radicular pain. The premise for the use for radiofrequency lesioning is to produce a partial lesion in the DRG so as to preferentially disrupt nociception while avoiding significant sensory deficit. The use of CRFL in cervical radicular pain has also been shown to be moderately effective in a small number of patients without significant long-term neurological complications (1-3). Van Wijk et all (4) suggested in a retrospective analysis that CRFL may exert a long lasting analgesic effect when applied to the DRG in patients with chronic lumbosacral radicular pain. However, in a follow-up randomized, double blind, controlled trial, Geurts et al (5) failed to show a difference between those patients treated with CRFL of the DRG for chronic lumbosacral radicular pain and the control group.

Because of the potential neurological complications of CRFL, pulsed radiofrequency lesioning (PRFL), an isothermal radiofrequency treatment of the cervical DRG for the management of chronic cervical radicular pain, has been recently advocated (6). PRFL is thought to exert its effect on neural tissue through electric fields rather than thermocoagulation, but its exact mechanism of action remains obscure (7). In a retrospective analysis of 13 patients, Teixeira et al (8) reported PRFL of the lumbar DRG or segmental nerve to be effective in treating sciatic-related pain from intervertebral disc herniation. Previously, a small case series has reported that chronic lumbosacral radicular pain may be palliated with PRFL resulting in months of relief (9).

Because the treatment for chronic lumbosacral radicular pain with PRFL remains contentious, we con- ducted a randomized prospective pilot study comparing patients treated with PRFL only to those treated with a combination of PRFL and CRFL. All patients provided written informed consent. We sought to:

1) evaluate and obtain insight into the safety of PRFL with respect to adverse neurological outcome

2) determine if the thermal aspects of radiofrequency offers any added therapeutic outcome and

3) if PRFL appears to be a potential option for treating chronic radicular pain that would warrant future controlled trials.

\section{Methods}

\section{Participants}

The Beth Israel Deaconess Medical Center Institutional Review Board approved this study, and all patients provided written informed consent. Patients who were seen in the Beth Israel Deaconess Medical Center Arnold Pain Center between November 2002 and November 2004 and met eligibility criteria were enrolled into the study. The inclusion criteria for the study were as follows:

- A greater than 6-month history of segmental pain of lumbar or sacral origin radiating from the back into the foot.

- Age over 18 years.

- Unsatisfactory pain control with oral pharmacotherapy and physical therapy.

- Absence of a chronic or progressive motor deficit.

- Absence of significant sensory deficit.

- No indication for percutaneous or open surgical intervention.

- Magnetic resonance imaging evidence of nerve root involvement.

- A response to epidurally administered depo-steroid of one month or less.

- Complete relief of radicular symptoms following low-volume segmental nerve block.

- Informed consent.

The exclusion criteria for the study are summarized as follows:

- Evidence of significant neurological deficit.

- Hypersensitivity to injected materials: local anesthetic, contrast, depo-corticosteroids.

- Coagulopathy.

- Significant psychopathology.

- Pending workman's compensation claims.

- Pregnancy.

- Language barrier. 


\section{Study Design}

All patients were interviewed and examined by physicians trained in interventional pain management. Patients were carefully assessed on physical exam for sensory, motor, or reflex deficit and carefully documented. Only patients with subtle neurological findings with complaints of lumbar or sacral radicular pain were to be randomized. Following failure of conservative treatment, which included interlaminar epidural steroid injections, all patients in the study were first treated with a diagnostic/therapeutic selective nerve root block with $1 \%$ lidocaine and depo-corticosteroid (40 milligrams) in a series of at least 3 injections spaced 1 month apart. Diagnostic blockade with local anesthetic had to produce temporary but complete pain relief of radicular symptoms as assessed by the recovery room nurse on 3 separate injections in order for a patient to be considered for this study. These blocks included the levels of L1-5 and S1. Patients were randomly assigned to one of 2 groups. Each patient in Group 1 was treated with PRFL at $42^{\circ} \mathrm{C}$ for 120 seconds only. During each second of a PRFL treatment, 2 bursts of 20-millisecond intervals delivered alternating current $(500,000 \mathrm{Hertz}\{\mathrm{Hz}\})$ to the surrounding tissue. The active 20 -millisecond phase was followed by a 480-millisecond phase to allow for heat dissipation. The voltage output was 45 . Each patient in Group 2 was treated with the identical PRFL protocol and upon completion of PRFL received CRFL to the maximum tolerated temperature that created a burning sensation from the low back to the foot. This temperature averaged $54^{\circ} \mathrm{C}+(5)$ for 60 seconds. The variation was because of the variable heat wash out at the nerve root. Temperatures were in the range of irreversible damage to neural structures. The radiofrequency lesion generator (RFG-3C Plus; Radionics, Inc., Burlington, MA) was used for all lesions. In both groups, RFL treatments were done without prior injection of local anesthetic onto the respective DRG or segmental nerve.

\section{Technique of a Diagnostic Segmental Nerve Root Block and Assessment}

C-arm radiography (Siemens, Siremobil, 2000) and water soluble, nonionic radiographic contrast was used to verify needle placement for the selective nerve root blocks prior to injection. With the patient in the prone position, the skin and subcutaneous tissue were infiltrated with $1 \%$ lidocaine after sterile preparation, and a 22-gauge spinal needle was inserted paravertebrally under fluoroscopic guidance. The end points of the needle placement for the lumbar levels were as follows:
1) On anteroposterior view, the needle was not advanced medially further than the lateral aspect of the corresponding pedicle.

2) On lateral view, the needle was placed in a retroneural position such that the needle tip was immediately dorsal to the respective spinal nerve, but not in the substance of the nerve or the dural and perineural sheath.

Nonionic contrast (isovue-M300, Bracco Diagnostics, Princeton NJ) was initially injected to outline the contour of the spinal nerve and determine the maximum volume of local anesthetic that would avoid significant central epidural spread. The volume of local anesthetic ranged between $0.5-1.0 \mathrm{~mL}$ of $2 \%$ preservative free lidocaine. For therapeutic purposes, a depo preparation of $40 \mathrm{mg}$ of methylprednisolone acetate was subsequently injected. For the $\mathrm{S} 1$ segmental nerve block similar patient positioning, skin infiltration, spinal needle, and injectates as well as volumes were used. The final needle position was as follows:

1) On the lateral view, the needle tip fell just short of contacting the ventral sacral floor.

2) The anteroposterior view the needle was just caudal to the $\mathrm{S} 1$ pedicle and in the middle to slightly medial to it.

The visualization of the posterior $\mathrm{S1}$ foramen was achieved by axial rotation of the C-arm until the L5/S1 disc space was clearly visualized, and with a slight ipsilateral rotation.

\section{Technique for PRF and CRFL of the Lumbar Dorsal Root Ganglion and Sacral Segmental Nerves}

All radiofrequency procedures were performed on the compromised spinal nerve root as identified by selective spinal nerve root block. One to 2 milliliters of $1 \%$ lidocaine were used for local anesthesia of the skin prior to the placement of the RF needle. A C-arm fluoroscopy machine was used for visualization during the sterile placement of the RF electrode (22-G, 10 $\mathrm{cm}$ needle, with a curved $10 \mathrm{~mm}$ active tip, Radionics, Burlington, MA). For the lumbar segments, the electrode was positioned in close approximation to the DRG. On fluoroscopy, this corresponded to the dorsal-cranial quadrant of the intervertebral foramen on lateral view (Fig. 1A) and on anteroposterior view the tip was located midway into the pedicle column (Fig. 1B). In cases of S1 nerve root treatment, the electrode was advanced through the posterior foramen with the target being the segmental nerve as it passes ventrally 


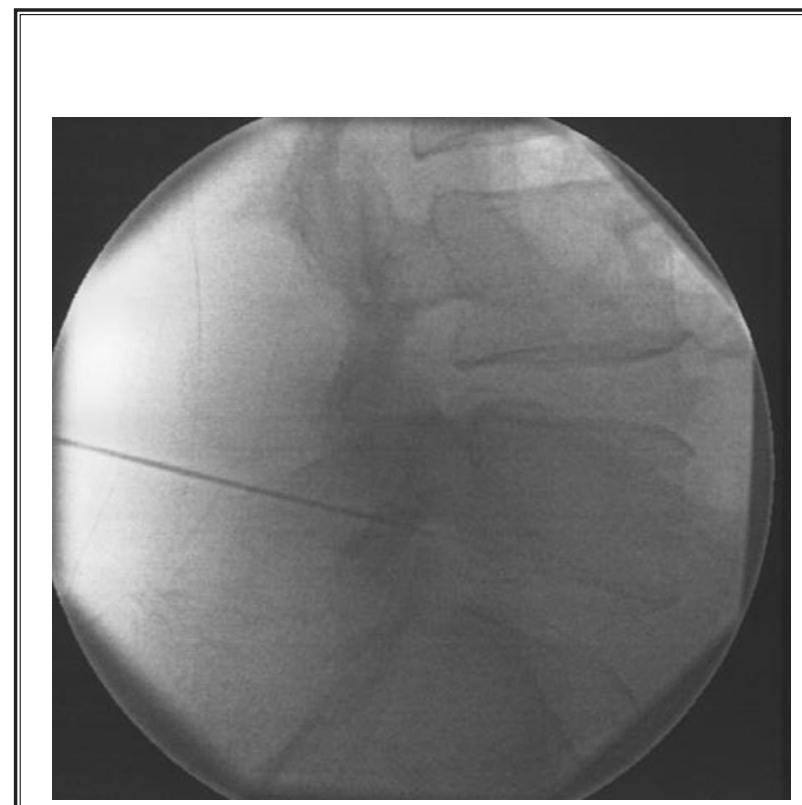

A. Lateral view of dorsal-cranial quadrant of intervertebral foramen.

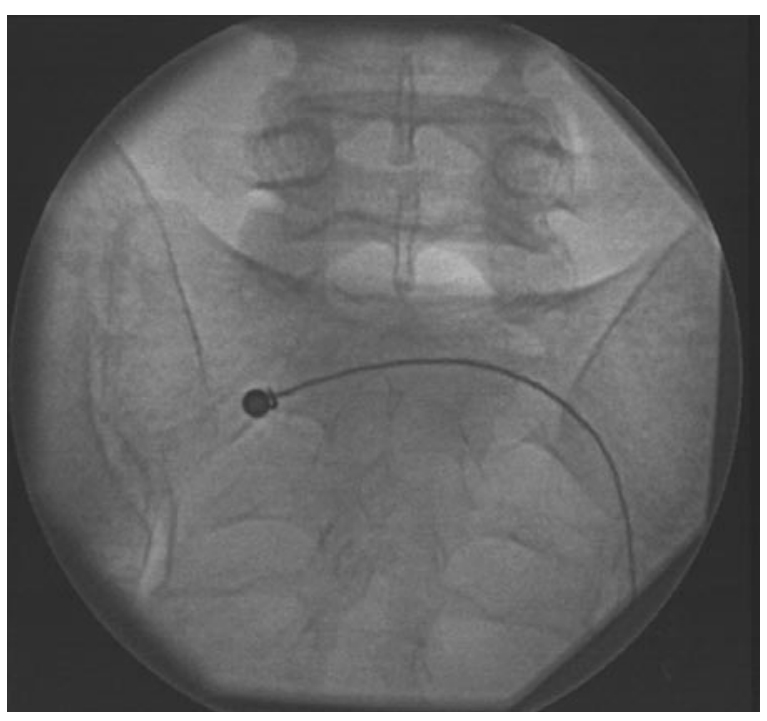

C. Needle positioning on anteroposterior view.

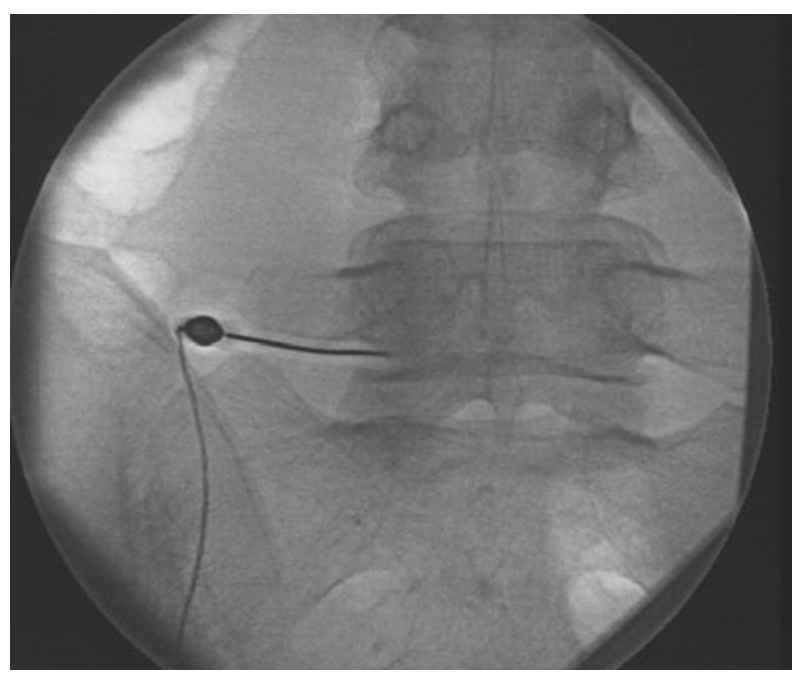

B. Anteroposterior view of tip midway into the pedicle column.

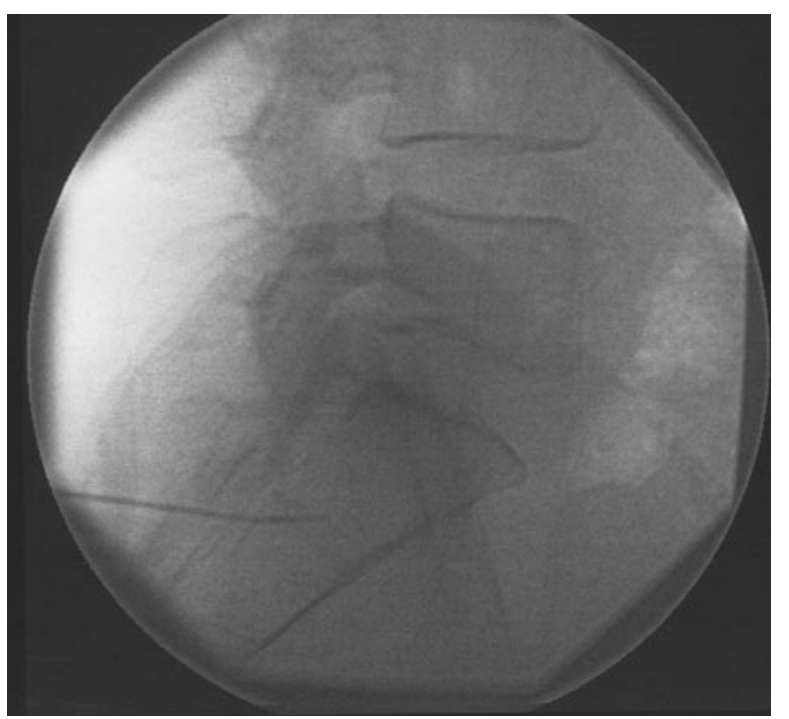

D. Tip advanced anterior border of the sacral canal on lateral projection.

Fig. 1. Fluoroscopy of the dorsal-cranial quadrant of the intervertebral foramen. 
though the anterior sacral formina; this is because of the inaccessibility of the DRG. The needle positioning on the anteroposterior view was similar to the $\mathrm{S} 1 \mathrm{seg}$ mental nerve block as described above (Fig. 1C). The tip was advanced anterior to the anterior border of the sacral canal on lateral projection (Fig. 1D). The degree of electrode advancement was dependent on the stimulation criteria outlined next.

Once the electrode was appropriately positioned, the stylet was then replaced by the radiofrequecy probe (SMK-TC 5, Radionics, Burlington, MA). The final positional requirements for each group treated were as follows:

1) Sensory stimulation $(50 \mathrm{~Hz})$ threshold under 0.6 volts that created paresthesia concordant to the usual chronic pain distribution; the stimulation must be felt down to the ankle/foot.

2) Motor stimulation (2 HZ) was greater than 1.5 times the sensory stimulation threshold.

3) Impedances were checked to ensure a complete electrical circuit and range from 200 to 400 Ohms.

\section{Evaluation}

Each patient's response to the treatment was followed up on subsequent visits to the pain center. Our primary outcomes were degree of pain relief and occurrence of any complications. At 8 weeks follow-up patients were screened for neurological complaints and deficits. Each of the participant's pain was evaluated for pain on a standard 10-point verbal analogue scale (VAS) with 0 being no pain, and 10 representing the worst pain imaginable. $A$ reduction of 2 points or more on the VAS was considered a clinically important reduction in the intensity of pain. Pain relief was considered a success if the treatment resulted in a VAS decrease of at least 2 and/or $30 \%$ for at least 8 weeks (10). Patients were followed on a monthly basis to determine the duration of relief.

\section{Statistics}

A 2-sided Fisher's exact test was used to calculate the statistical significance of the results. A Kaplan-Meier survival curve was constructed to determine the time-dependent success rate and a BoxWhisker was used to analyze the distribution (11). All calculations were done using the MedCalc statistical program.
Table 1. Demographics.

\begin{tabular}{|c|c|c|c|}
\hline & & $\begin{array}{c}\text { PRFL } \\
\text { (37) }\end{array}$ & $\begin{array}{c}\text { PRFL \& CRFL } \\
\text { (39) }\end{array}$ \\
\hline Age in year & $\operatorname{an} \pm \mathrm{SD}$ ) & $55.1 \pm 14.3$ & $53.8 \pm 14$ \\
\hline Number of & Male & 19 & 26 \\
\hline & Female & 18 & 13 \\
\hline $\begin{array}{l}\text { Number of } \\
\text { previous ba }\end{array}$ & $\begin{array}{l}\text { nts with } \\
\text { rgeries }\end{array}$ & 5 & 8 \\
\hline $\begin{array}{l}\text { Duration (y } \\
\text { symptoms }\end{array}$ & $\begin{array}{l}\text { adicular } \\
\mathrm{n} \pm \mathrm{SD})\end{array}$ & $3.2 \pm 1.7$ & $3.1 \pm 1.8$ \\
\hline
\end{tabular}

\section{Results}

A total of 76 patients were enrolled based on the inclusion/exclusion criteria. Thirty-seven patients were treated with PRFL and 39 patients with PRFL and CRFL. The patients' characteristics and baseline values did not differ between the 2 treated groups, and are outlined in Table 1. Table 2 indicates the levels of involvement and hence RF treatments, with the majority at the L5 level followed by S1. The impact on VAS for the 2 treatment groups as well as the percentage with a clinically successful (as defined by a reduction in VAS by 2 and/or a $30 \%$ decline) response at 2 months is outlined in Table 3. There was no significant difference in the percentage of successful response rate or in the average decline in VAS between the 2 groups. There were no neurological deficits such as motor loss or dermatomal hyposensitivity in either of the 2 treatment groups. Complaints related to neuritis such as burning dermatomal pain or dysesthesias were screened for, but none were found.

The Kaplan-Meier curve (Fig. 2) was used to display the time dependent success of treatment for both treatment groups. For both treatment groups there was a steep loss of analgesic effect between 2 to 4 months. By the eighth month, the vast majority of patients returned to their baseline pain intensity. Fig. 3 indicates the average time of success in responders following treatment with either PRFL or PRFL and CRFL. The average duration was $3.18( \pm 2.81)$ months 
Table 2. Level of Radiofrequency.

\begin{tabular}{|l|c|c|c|c||}
\hline \multirow{2}{*}{ Level } & \multicolumn{2}{|c|}{ PRFL } & \multicolumn{2}{c|}{ PRFL \& CRFL } \\
\cline { 2 - 5 } & $\begin{array}{c}\text { Number of } \\
\text { patients }\end{array}$ & $\%$ & $\begin{array}{c}\text { Number of } \\
\text { patients }\end{array}$ & \% \\
\hline \multirow{2}{*}{ L1 } & 0 & - & 1 & 2.6 \\
\hline L2 & 2 & 5 & 1 & 2.6 \\
\hline L3 & 0 & - & 1 & 2.6 \\
\hline L4 & 0 & - & 1 & 2.6 \\
\hline L5 & 20 & 54 & 18 & 46 \\
\hline S1 & 3 & 8 & 7 & 48 \\
\hline L4 \& L5 & 4 & 11 & 1 & 2.6 \\
\hline L5 \& S1 & 8 & 22 & 9 & 23 \\
\hline Two Level RF & 12 & 33 & 10 & 25.6 \\
\hline One Level RF & 25 & 67 & 29 & 74.4 \\
\hline
\end{tabular}

Table 3. Average VAS and Duration.

\begin{tabular}{|l|l|l|}
\hline & PRFL & $\begin{array}{l}\text { PRFL \& } \\
\text { CRFL }\end{array}$ \\
\hline $\begin{array}{l}\text { Average VAS score - Before } \\
\text { treatment }\end{array}$ & $7.8 \pm 1.6$ & $7.1 \pm 1.9$ \\
\hline $\begin{array}{l}\text { Average VAS score - After } \\
\text { treatment (at 8 weeks) }\end{array}$ & $3.5 \pm 3.4$ & $2.3 \pm 2.2$ \\
\hline Average VAS difference & $4.24 \pm 3.2$ & $4.8 \pm 3.0$ \\
\hline $\begin{array}{l}\text { Average duration+ of success in } \\
\text { months }\end{array}$ & $3.18 \pm 2.81$ & $4.39 \pm 3.5$ \\
\hline
\end{tabular}

Mean \pm SD

+ - months until the VAS increase to baseline VAS in those treated with PRFL and $4.39(+3.5)$ months in those treated with both CRFL and PRFL. There was no statistical difference in the duration of analgesic benefit between the 2 groups.

\section{Discussion}

PRFL has recently gained popularity in the treatment of spinal pain including acute and chronic lumbar radicular pain (7-9). All of these small studies have suggested the safety and potential efficacy in the treatment of lumbar root pain using PRFL, emphasizing its nondestructive nature. In our study, we were unable to detect neurological deficits or adverse painful side effects from PRFL. These present findings are consistent with the previous observations of Van Zundert et al (6) in which PRFL was applied to the cervical DRG. We conclude that PRFL appears to be safe in its application to the lumbar DRG and segmental nerves.

There probably exists a significant margin of safety because no neurological deficits were found in patients treated with PRFL and CRFL. However subclinical destruction of cell structure in the DRG is likely. CRFL temperatures above $45^{\circ} \mathrm{C}$ have been demonstrated to cause the breakdown of myelin, nerve cell necrosis, and hemorrhage (12). The damage to neuronal subtypes is no longer believed to preferentially affect C fibers, and thus heating the DRG or segmental nerve with CRFL will lesion all fiber types indiscriminately (13). More recently, Erdine et al (14) showed that both CRFL and PFRL disrupt cell substructures in the DRG of rabbits. The electrical as well as thermal fields produced during a PRFL treatment have recently been pointed out by Cosman and Cosman (15) to have the potential to cause tissue disruption. Patients in our study likely did not present with neurological findings because there were enough neurons left intact to allow for normal sensation and function. Complaints of painful dysesthesias were likely avoided because the applied temperatures to the DRG/segmental nerve were increased to the maximum tolerable level, and no local anesthetic was administered prior to lesioning.

We were unable to demonstrate a significant therapeutic advantage to adding CRFL to PRFL. In the group treated with both PRFL and CRFL there was a tendency towards more patients responding with a longer duration and more improvement in VAS compared to those patients treated only with PRFL, but there was no statistical difference. Partial heat destruction of neurons by CRFL did not appear to add any 


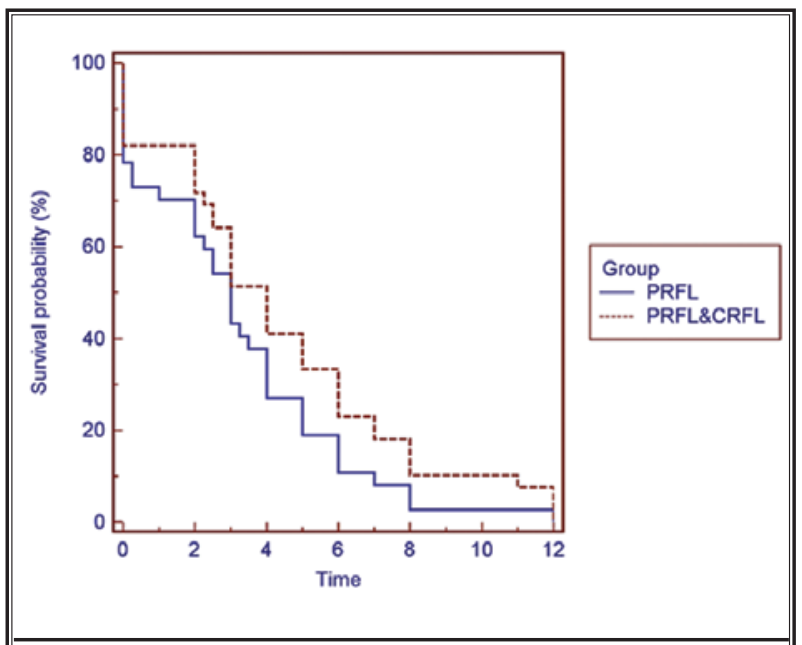

Fig. 2. Kaplan-Meier Survival Curve.

*Time=months.

Time dependent success of treatment is presented for both treatment groups using the Kaplan-Meier method, as survival curve. In both groups half of the patients treated approach their pretreatment pain levels at the 3 to 4 months intervals. By the eighth month the vast majority of the patients have lost any treatment benefit.

clinical benefit. Our data are consistent with the results observed by Slapendel et al (2) where the authors demonstrated that treatment of the cervical DRG at $40^{\circ} \mathrm{C}$ was equally as effective as $67^{\circ} \mathrm{C}$. They suggested that electrical fields might be important in the clinical effects of radiofrequency therapy.

The mechanism of action of PRFL remains poorly understood and the technique is likely not entirely without tissue injury as once thought. It is at present hypothesized that PRFL induces changes in gene expression in the dorsal horn (16). Application of PRFL as well as CRFL to the cervical DRG in the rat has been shown to increase neuronal cell activity in the dorsal horn. C-fos nuclear binding protein, which is involved in triggering long-term changes in gene expression, is used as a marker for activated neurons (17). Interestingly, both the ipsilateral as well as contralateral dorsal horn (Lamina I and II) demonstrated increased C-fos expression 7 days postradiofrequency treatment of the rat cervical DRG (18). There was no detectable difference in dorsal horn cell activity between rats treated with PRFL or CRFL. The authors concluded that temperature is not an important factor in affecting dorsal horn C-fos expression. PRFL is thought to induce an electric field in the regions of the DRG and

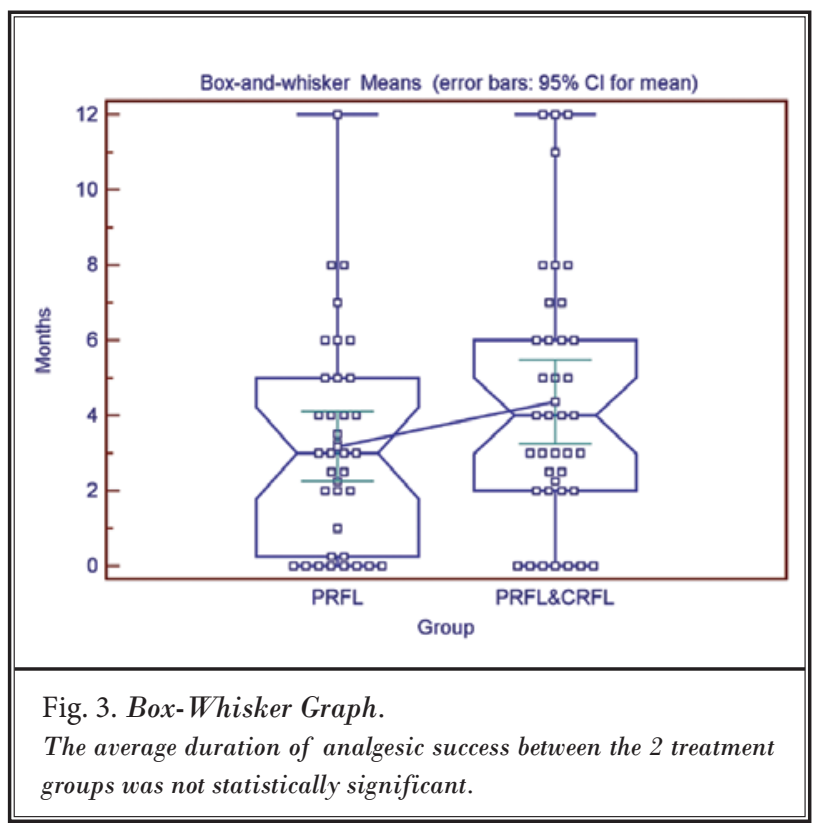

dorsal root entry zone at the cervical level, and influence local neuronal function.

In the lumbar region it may be hypothesized that PRFL of the DRG and/or segmental nerve induces through unidentified mechanisms neuronal changes in the dorsal horn. The electric charge of the cannula is thought to create an electric field in the surrounding space; that field in turn exerts a force on any other charge in space $(19,20)$. The force exerted on charged particles causes motion, which in turn generates current. How this induces changes in C-fos expression in the dorsal horn as well as its role in pain modulation remains unknown. Unfortunately, there are no preclinical studies on the effects of pulsed or continuous radiofrequency lesioning of the lumbar DRG and the changes to the dorsal horn.

The positive response rate $(70 \%)$ to PRFL treatment and average duration of sustained improvement in this study was similar to that appreciated by other investigations in the cervical region (6). These results could reflect placebo response, regression to the mean, or spontaneous improvement. There is a sharp deterioration in analgesic benefit of PRFL between 2 to 4 months (Fig. 2). The decline in treatment benefit probably reflects some proportional loss of placebo and actual treatment effects. We are unable to draw conclusions about the efficacy of PRFL on chronic radicular pain at this point. The technique seems to be 
safe and therefore a safe, randomized, controlled trial may be carried out.

\section{Conclusion}

Based on our findings in the present study, we conclude that PRFL of the DRG/segmental nerve appears to be a useful and safe treatment for chronic segmental pain radiating to the leg. This modality may be an option when the injection of depo-corticosteroids do not afford adequate duration of analgesia, and the patient is not a candidate or does not de- sire more invasive options (surgical decompression or spinal cord stimulation). However, the analgesic effect is time limited and in a significant number of patients may not exceed 3 months. In those individuals who do respond favorably to pulsed radiofrequency, this modality avoids the complications of steroid injections as well as potential long-term complications $(21,22)$. Lastly, determination of the actual efficacy of pulsed radiofrequency lesioning in the treatment of chronic lumbosacral radicular pain awaits further prospective controlled trials.

\section{References}

1. Van Kleef M, Dingemans W, Barendse GAM, Floor E, Sluijter ME. Effects and side effects of a percutaneous thermal lesion of the dorsal root ganglion in patients with cervical pain syndrome. Pain 1993; 52:49-53.

2. Slappendel R, Crul BJP, Braak GJJ, Geurts JWM, Booij LH, Voerman VF, de Boo $T$. The efficacy of radiofrequency lesioning of the cervical spinal dorsal root ganglion in a double blinded randomized study: No difference between $40^{\circ} \mathrm{C}$ and $67^{\circ} \mathrm{C}$ treatments. Pain 1997 ; 73:159-163.

3. Van Kleef M, Liem L, Lousberg R, Barendse G, Kessels F, Sluijter M. Radiofrequency lesion adjacent to the dorsal root ganglion for cericobrachial pain: A prospective double blind randomized study. Neurosurgery 1996; 38:11271132.

4. Van Wijk RMAW, Geurts JWM, Wynne HJ. Long-lasting analgesic effect of radiofrequency treatment of the lumbar dorsal root ganglion. J Neurosurg (Spine 2) 2001; 94:227-231.

5. Geurts JWM, van Wijk RMAW, Wynne HJ, Hammink E, Buskens E, Lousberg R, Knape JTA, Groen GJ. Radiofrequency lesioning of dorsal root ganglia for chronic lumbosacral radicular pain: A randomized, double-blind, controlled trial. The Lancet 2003; 361:21-26.

6. Van Zundert J, Lamé IE, de Louw A, Jansen J, Kessels F, Patijn J, van Kleff $M$. Percutaneous pulsed radiofrequency treatment of the cervical dorsal root ganglion in the treatment of chronic cervical pain syndromes: A clinical audit. Neuromodulation 2003; 6:6-14.

7. Sluijter ME, Cosman ER, Rittman WB, Van Kleef $M$. The effects of pulsed radiofrequency fields applied to the dorsal ganglion-a preliminary report. The Pain Clinic 1998; 11:109-117.

8. Teixeira A, Grandinson M, Sluijter ME. Pulsed radiofrequency for radicular pain due to a herniated intervertebral disc-An initial report. Pain Practice 2005; 5:111-115.

9. Munglani R. The longer term effect of pulsed radiofrequency for neuropathic pain. Pain 1999; 80:437-439.

10. Farrar JT, Young JP, LaMoreaux J, Werth JL, Poole RM. Clinical importance of changes in chronic pain intensity measured on an 11 point numerical pain rating scale. Pain 2001; 94:149-158.

11. Bland J, Altman D. Survival probabilities (the Kaplan-Meier method). BMJ 1998; 317:1572.

12. Smith HP, McWhorter JM, Challa VR. Radiofrequency neurolysis in a clinical model. J Neurosurg 1981; 55:246-253.

13. De Louw AJA, Vles HSH, Freling G, Herpers MJHM, Arends JW, van Kleef $M$. The morphological effects of a radiofrequency lesion adjacent to the dorsal root ganglion (RF-DRG) - An experimental study in the goat. European J Pain 2001; 5:169-174.

14. Erdine S, Yucel A, Cimen A, Aydin S, Sav A, Bilir A. Effects of pulsed versus conventional radiofrequency current on rabbit dorsal root ganglion morphology. Eur J Pain 2005; 9:251-256.

15. Cosman ER Jr, Cosman ER Sr. Electric and thermal field effects in tissue around radiofrequency electrodes. Pain Medicine 2005; 6:405-424.

16. Higuchi Y, Nashold BS, Sluijter M, Cosman E, Pearlstein RD. Exposure of the dorsal root ganglion in rats to pulsed radiofrequency currents activates dorsal horn lamina I and II neurons. Neurosurgery 2002; 50:850-856.

17. Bullitt E. Expression of c-fos like protein as a marker for neuronal activity following noxious stimulation in the rat. J Comp Neuol 1990; 296:517-530.

18. Van Zundert J, de Louw AJA, Joosten EAJ, Kessels AGH, Honing W, Dederen J, Veening, JG, Vles JSH, van Kleef M. Pulsed and continuous radiofrequency current adjacent to the cervical dorsal root ganglion of the rat induces late cellular activity in the dorsal horn. Anesthesiology 2005; 102:125-131.

19. Sluijter ME, Racz GB. Technical aspects of radiofrequency. Pain Practice 2002; 2:195-200.

20. Sluijter ME. Radiofrequency Part I, Chapter 3. Flivopress: Meggen, Switzerland. 2001: 49-72.

21. Houten JK, Errico TJ. Paraplegia after lumbosacral nerve root block. The Spine Journal 2002; 2:70-75

22. Manchikanti L. Role of neuraxial steroids in interventional pain management. Pain Physician 2002; 5:182-199. 